\title{
Demographic Antecedents of Consumer Cosmopolitanism and Ethnocentrism: A Country-Level Analysis with Twenty-Eight Countries
}

\author{
C. Min Han \\ School of Business, Hanyang University, Seoul, Korea
}

\begin{abstract}
The purpose of this study is to empirically investigate demographic antecedents of cross-country differences in consumer cosmopolitanism (COS) and consumer ethnocentrism (CET) with samples of twenty-eight countries. Specifically, we examine gender and age level differences in COS and CET for individual countries and assess the consistency of the differences across countries. The findings of this study show that COS is high in countries of low median age. Additionally, our study found that CET is high in countries with large populations. When CET was examined with dogmatism and patriotism dimensions, dogmatism was found to be high in high median age countries. Our study also found a moderate tendency across countries for older consumers exhibiting higher levels of ethnocentrism, dogmatism, and patriotism.
\end{abstract}

Key words: Consumer cosmopolitanism, consumer ethnocentrism, cross-country analysis,

\section{INTRODUCTION}

Consumer cosmopolitanism (COS) and consumer ethnocentrism (CET) have been extensively studied in the field of international marketing. Research has shown that COS has positive effects on consumer choices for foreign brands, while CET encourages consumer choices for domestic products [1] [2]. In spite of the large body of literature concerning the buying behavior of cosmopolitan and ethnocentric consumers, relatively few studies have investigated cross-country differences in the levels of COS and CET. Our study is designed to investigate the crosscountry differences in COS and CET with samples of twenty-eight countries. Specifically, we examine gender and age level differences in COS and CET for individual countries and assess the consistency of the differences across countries. These issues have been examined but only with samples from a small number of countries in the past.

\section{RELEVANT LITERATURE}

Past studies have examined demographic antecedents of individual-level cosmopolitanism. Past studies tended to suggest that young consumers were more cosmopolitan [3][4]. Cleveland et al. [1] reported such tendency in three out of eight countries they examined. One might attribute this tendency to the fact that young individuals are more open-minded towards more diverse, or emergent ideas and values [5] and also tend to engage in more cosmopolitan activities such as overseas travel and internet surfing [1].

There appears to be a gender difference in cosmopolitanism as well. Cleveland et al [1] found in a study on eight countries that women are more cosmopolitan in four countries. A similar relation was also reported in Robertson and Zill [6] and Cleveland et al [7]. As Meyers-Levy [8] suggests, women may be predisposed towards harmonizing relations between themselves and disparate parties and cultures, whereas men tend to be more selffocused and pursue mastery and self-assertion. But no gender differences were found in Riefler et al. [9].

Regarding demographic characteristics related to CET, there may also be an age effect: older consumers tend to be more conservative and ethnocentric [10][11]. On the other hand, the youth may be more likely influenced by increasing globalization and cosmopolitanism. However, no relationship was found between age and ethnocentrism in Festervand et al. [12] and Sharma et al. [13].

Gender was another demographic factor considered as a correlate of CET. Research shows that female consumers tend to be more ethnocentric [10][11] and more patriotic [14]. Josiassen et al [11] argues that women are more conservative and collectively minded than men. Conservatism and collective mindedness may lead to greater CET. However,

Corresponding Author: C. Min Han, School of Business, Hanyang University, Seoul, Korea, cmhlab@ hanyang.ac.kr 


\section{Min Han/International Journal of Business and Management, 2(5) 2018, Pages: 30-35}

Bannister and Saunders [15] found that men are more ethnocentric and Caruana and Magri [16] showed no relationship. Overall, empirical evidence does not appear to be consistent when considering age and ethnocentrism.

\section{HYPOTHESES}

Demographic differences across countries may affect country-level COS and CET. As discussed earlier, research shows that younger generations are more open-minded towards different ideas and values [5] and also tend to engage in more cosmopolitan activities such as overseas travel, internet use, and foreign product consumption [1]. In addition, older people have more ethnocentric tendencies than younger people because they are generally more conservative and less inclined towards imports [17][13]. Likewise, countries with large younger populations (i.e. low median age) may show a high level of COS and a low level of CET than countries with a small younger population (i.e. high median age). Thus, one might suggest the following hypotheses:

H1: COS (CET) will be higher in countries with large (small) younger populations than in countries with small (large) younger populations.

Another demographic antecedent concerns population size. The size of a population may have mixed effects on COS and CET. On the one hand, large populations may provide environments suitable for cultural diversity, cultural interactions, and innovations [18]. Thus, consumers in countries with large populations may possess greater intercultural capacities and as a result, may be more accommodating and less hostile towards foreign cultures and products. But, on the other hand, countries with large populations may be less economically dependent on foreign cultures and products because of well-developed local offerings. They are, then, less cosmopolitan and more ethnocentric. Small countries in population such as Singapore and Hong Kong may have no choice but to be more cosmopolitan because of limited domestic alternatives. Taken together, the link between population size and COS and CET is not very clear-cut; additional empirical investigation is most likely required. Although alternative hypotheses are plausible, we posit the following hypotheses.

$\mathrm{H} 2$ : COS (CET) will be higher in countries with small (large) populations than in countries with large (small) populations.
We also examine cross-country applicability of demographic antecedents. Empirical findings broadly support the cross-country applicability of age and gender as COS and CET antecedents, though the relationships vary considerably across countries. We propose the following hypotheses regarding cross-country applicability of age and gender as antecedents.

H3: The gender difference in COS and CET will be found consistently across countries.

H4: The age level difference in COS and CET will be found consistently across countries.

\section{RESEARCH METHOD}

Multiple item scales were developed to measure COS and CET. These items were based on previous research as mentioned above and were modified to fit the context of this study better. They were measured on a seven point Likert scale (1=strongly disagree, $7=$ strongly agree). Regarding the COS measurements, we developed nine items based on the items used in previous studies by Cleveland and Laroche [19], Cleveland et al [1], and Riefler et al. [9]. As for demographic antecedents of the twentyeight countries examined, we collected secondary data from multiple sources. Finally, we assessed the age level of individuals based on five age categories (under $19=1,20$ to $29=2,30$ to $39=3,40$ to $49=$ 4,50 or over $=5$ ).

Sample and Data Collection: To assess the levels of cosmopolitan and ethnocentric tendencies of twenty-eight countries, on-line surveys were conducted with two hundreds individuals, one hundred for each gender and from each country. We obtained individual panels from a global survey institute. By offering a monetary incentive to each participant, we obtained a total of five thousand six hundred respondents across twenty-eight countries. On average, each respondent was in their twenties or thirties $(68.0 \%)$ and employed or self-employed $(71.1 \%)$. Individual country samples showed similar characteristics across countries.

Scale Validation: In order to test for internal consistency, we calculated a Cronbach's alpha coefficient for each set of measurement items that comprised COS and CET for each country. These values ranged from .840 (Chile) to .935 (Hong Kong) for COS and from .863 (Egypt) to .940 (UK). All values surpassed the recommended level of .70 (Nunnally 1978) [20]. We also examined composite construct reliability. The composite reliability for all countries combined was .881 for COS and .927 for CET, exceeding the suggested level of .70 (Bagozzi, 1980) [21]. 


\section{Min Han/International Journal of Business and Management, 2(5) 2018, Pages: 30-35}

Descriptive Statistics: The mean scores of COS and CET for each country indicate that our samples of twenty-eight countries were modestly cosmopolitan and not extremely ethnocentric. The grand mean scores of COS and CET for all countries were 4.81 and 3.85 , respectively. As for individual countries, Mexico $(\mathrm{m}=5.20)$ was the most cosmopolitan and Japan the least $(\mathrm{m}=3.95)$ among our country samples. On the other hand, Indonesia scored the highest and Kazakhstan was the lowest on CET with scores of 5.04 and 2.36, respectively. We also examined CET scores on dogmatism and patriotism, the two factors we identified. Regression factor scores for individual countries were obtained from factor analysis. The results indicate that the dogmatic and patriotic dimensions of CET produced sharply different distributions of scores across countries compared to that from all ten CET items. In the dogmatic dimension, Japan scored the highest while Egypt scored the lowest. On the other hand, Egypt was found to be the most patriotic country and Germany was the least.

Table 1 Correlation matrix

\begin{tabular}{|c|c|c|c|c|c|c|}
\hline & $\mathrm{COS}$ & CET & Dogmatism & Patriotism & $\begin{array}{l}\text { Median } \\
\text { age }\end{array}$ & Population \\
\hline COS & 1 & & & & & \\
\hline CET & .245 & 1 & & & & \\
\hline Dogmatism & .022 & $.727^{* * *}$ & 1 & & & \\
\hline Patriotism & $.348^{*}$ & $.729^{* * *}$ & .061 & 1 & & \\
\hline $\begin{array}{l}\text { Median } \\
\text { age }\end{array}$ & $-.430^{* *}$ & -.184 & $.318^{*}$ & $-.591^{* * * *}$ & 1 & \\
\hline Population & -.101 & $.374^{*}$ & .307 & .238 & -.130 & 1 \\
\hline
\end{tabular}

\section{RESULTS OF HYPOTHESES TESTING}

In order to investigates demographic antecedents of country differences in COS and CET, we examined bivariate correlations of COS and CET with antecedents. We chose the bivariate method because we analyzed twenty-eight cases in our study. Hair et al. (2006, p. 174) [22] recommended the use of a bivariate analysis for a small sample under thirty cases. Correlations are shown in Table 1.

Table 1 shows that COS was negatively correlated with the median age of the population $(r=-.430, p<$ $.05)$. COS was higher in countries with large younger populations. This finding supports H10-1. However, no relationship was found between COS and the size of a population.

As regards to the CET of individual countries, population size was found to be positively correlated to CET. The correlation coefficient as shown in Table 1 was $.374(\mathrm{p}<.05)$. This finding suggests that CET was higher in countries with large populations, thus supporting H11-2. When we examined CET, taking into account dogmatism and patriotism factors, median age was found to be correlated to CET while population size was not. Interestingly, median age appeared to have mixed effects on CET. Specifically, median age was a moderately positive correlate to dogmatism $(\mathrm{r}=.318, \mathrm{p}<.10)$ and negatively related to patriotism $(\mathrm{r}=-.591, \mathrm{p}<.01)$. These findings suggest that countries with large younger populations (i.e. low median age) tend to exhibit stronger patriotic, but moderately less dogmatic tendencies than countries with small younger populations (i.e. high median age).

Cross-Country Applicability Tests of Demographic Antecedents: We hypothesized in $\mathrm{H} 3$ and $\mathrm{H} 4$ that the gender and age level differences in COS and CET exist consistently across countries. First, we carried out $\mathrm{t}$-tests to assess the statistical significance of the gender differences for each country. These t-test results are presented in Table 2. Table 2 depicts gender showing a higher level . 
C. Min Han/International Journal of Business and Management, 2(5) 2018, Pages: 30-35

Table 2 Results of t-tests on gender differences and correlation coefficients with age for COS and CET

\begin{tabular}{|c|c|c|c|c|c|c|c|c|}
\hline \multirow{2}{*}{ Countries } & \multicolumn{4}{|c|}{ Gender differences - t-test results } & \multicolumn{4}{|c|}{ Correlation coefficients with age } \\
\hline & $\cos$ & CET & Dogmatism & Patriotism & $\cos$ & CET & Dogmatism & Patriotism \\
\hline Taiwan & - & - & - & - & - & $.151^{* * *}$ & - & $.158^{* *}$ \\
\hline Malaysia & - & - & $\mathrm{M}^{*}$ & $\mathrm{~F}^{* *}$ & - & - & - & $.126^{*}$ \\
\hline Vietnam & - & - & - & - & - & - & - & - \\
\hline Singapore & - & - & - & - & - & - & - & - \\
\hline India & - & - & - & - & - & - & - & - \\
\hline Indonesia & - & - & - & - & - & - & - & $.122^{*}$ \\
\hline Japan & - & - & - & - & - & - & $.142^{* *}$ & - \\
\hline China & - & - & - & - & - & - & - & - \\
\hline Kazakhstan & - & - & - & - & $-.227^{* * * *}$ & - & - & - \\
\hline Thailand & $\mathrm{F}^{*}$ & - & - & - & - & - & - & - \\
\hline Australia & - & - & $\mathrm{F}^{*}$ & - & - & - & $-.128^{*}$ & $.193^{* * * *}$ \\
\hline Hong Kong & - & - & - & - & - & - & - & - \\
\hline Mexico & - & $\mathrm{M}^{* *}$ & - & $\mathrm{M}^{*}$ & - & - & - & - \\
\hline USA & - & - & - & - & - & - & - & $.140^{* *}$ \\
\hline Brazil & - & $\mathrm{M}^{* *}$ & - & $\mathrm{M}^{* * *}$ & - & - & - & - \\
\hline Chile & - & - & - & - & - & $.192^{* * *}$ & - & $.255^{* * * *}$ \\
\hline Canada & - & - & - & - & - & - & - & - \\
\hline Germany & - & - & - & - & - & - & - & $.174^{* *}$ \\
\hline Russia & - & $\mathrm{M}^{*}$ & - & $\mathrm{M}^{* * *}$ & - & - & - & - \\
\hline Spain & - & - & $\mathrm{F}^{*}$ & $\mathrm{M}^{* *}$ & - & $.258^{* * *}$ & $.238^{* * *}$ & $.122^{*}$ \\
\hline UK & - & - & - & - & - & - & - & - \\
\hline Italy & - & - & $\mathrm{F}^{* *}$ & - & - & $.138^{*}$ & - & $.138^{*}$ \\
\hline Poland & $\mathrm{F}^{*}$ & - & - & - & - & - & - & $.150^{* *}$ \\
\hline France & $\mathrm{F}^{*}$ & - & $\mathrm{F}^{* * *}$ & - & - & - & - & - \\
\hline South Africa & $\mathrm{M}^{* * *}$ & - & - & - & - & - & - & - \\
\hline UAE & - & - & - & - & - & - & - & - \\
\hline Egypt & - & - & - & - & - & - & - & - \\
\hline Turkey & - & $\mathrm{M}^{* *}$ & - & $\mathrm{M}^{* *}$ & - & - & - & $.171^{* *}$ \\
\hline
\end{tabular}

Note: $\mathrm{M}$ and $\mathrm{F}$ denote the gender showing a high level. $* * * \mathrm{p}<.01, * * \mathrm{p}<.05, * \mathrm{p}<0.1$ 


\section{Min Han/International Journal of Business and Management, 2(5) 2018, Pages: 30-35}

COS and CET at the .05 level for twenty-eight countries. Our gender difference tests indicate that males exhibited higher COS in only one country (South Africa) and greater CET in three (Mexico, Russia, and Turkey) out of the twenty-eight countries we examined. In addition, dogmatism was higher with females in two countries (Italy and France) and patriotism was higher with males in four countries (Brazil, Russia, Spain, and Turkey) and with females within a single country (Malaysia). These findings suggest that gender may not be an important antecedent of COS across countries. Additionally, males may be more ethnocentric and patriotic in some countries, but gender differences in CET were not be consistent across countries.

Furthermore, we investigated the age level differences in COS and CET across countries. For this purpose, we examined correlations of the age level in conjunction with COS and CET. As previously indicated, subject age level was assessed on a five-point scale. Correlations showing statistical significance at the .05 level are presented in Table 2. Table 2 shows that the value was significant with COS in only one country (Kazakhstan, $\mathrm{r}=-.227, \mathrm{p}<.01$ ). As for CET, positive correlations were found in three countries (Taiwan, Chile, and Spain) for all CET items combined, two (Japan and Spain) for dogmatism and seven (Taiwan, Australia, USA, Chile, Germany, Poland, and Turkey) for patriotism. There appears to be a moderate tendency across countries showing older consumers to be more ethnocentric, dogmatic, and patriotic. This tendency was found in several countries.

\section{DISCUSSION}

We sought to empirically investigate cross-country differences in COS and CET and their demographic antecedents using the samples of twenty-eight countries. We also examined gender and age level differences in COS and CET for individual countries and assessed the consistency of these differences across countries. These cross-countries issues have not been rigorously addressed in past studies. Several academic and marketing implications may be drawn from the findings of our investigation.

First, our findings suggest that COS may be high in countries of low median age. Second, Second, CET was correlated to population size, suggesting that CET may be high in countries with large populations. This finding contrasts with those by Shennan [18] who argued that large populations provide environments suitable for cultural diversity and interactions. Countries with large populations may be less economically dependent on foreign products because of well-developed local offerings.
Third, our study found that dogmatism was high in high median age countries while patriotism was high in countries of low median age. An intriguing contrast to note is that high median age countries exhibited strong levels of dogmatism but weak levels of patriotism. This may suggest that dogmatism and patriotism may be independent constructs and thus should be treated accordingly in operationalizations of CET as previously suggested by Shimp and Sharma [23], Caruana and Magri [16], and Balabanis et al. [17].

Finally, our study did not find cross-country consistency regarding gender differences for COS and CET. However, there was a moderate tendency across countries for older consumers exhibiting higher levels of ethnocentrism, dogmatism, and patriotism. These results are not surprising in light of the conflicting findings reported from past studies on gender and age factors.

\section{CONCLUSIONS}

Overall, our findings suggest that demographics can be useful antecedents for cross-country differences in COS and CET. The findings can contribute to our understanding on demographics and consumer behavior toward domestic vs. foreign products.

There are several marketing implications to our study as well. First, our findings may help multinational firms predict which countries present more opportunities for their products and brands. Particularly, firms may be likely to find cosmopolitan consumers in countries with large young populations. On the other hand, consumers may prefer local products in countries with large populations. Multinational firms may use these demographic characteristics for country segmentation and targeting. Additionally, firms can use predicted COS and CET levels in devising standardization - adaptation levels for local marketing in individual country-markets.

There were several limitations to this study. First, our study examined only twenty-eight countries, ultimately preventing us from employing more rigorous statistical methods. In addition, a different set of country samples might have yielded significantly different levels of COS and CET across countries. Therefore, our findings should be taken with some degree of cautions. Another limitation of our study is that we only examined a few demographics. Other demographics including income and education should be included in future studies. 


\section{REFERENCES}

[1] Cleveland, M., Laroche, M., \& Papadopoulos, N. 2009. Cosmopolitanism, consumer ethnocentrism, and materialism: An eightcountry study of antecedents and outcomes. Journal of International Marketing, 17: 116-146.

[2] Sharma, P. 2011. Country of origin effects in developed and emerging markets: Exploring the contrasting roles of materialism and value consciousness. Journal of International Business Studies, 42: 285-306.

[3] Riefler, P., \& Diamantopoulos, A. 2009. Consumer cosmopolitanism: Review and replication of the CYMYC scale. Journal of Business Research, 62: 407-419.

[4] Schueth, S., \& O'Loughln, J. 2008. Belonging to the world: Cosmopolitanism in geographic contexts. Geoforum, 39: 926-941.

[5] De Mooij, Marieke. 2004. Consumer behavior and culture: Consequences for global marketing and advertising. Thousand Oaks, CA: Sage Publications.

[6] Robertson, J. P., \& Zill, N. 1997. Matters of culture. American Demographics, 19: 48-52.

[7] Cleveland, M., Erdogan, S., Arikan, G., \& Poyraz, T. 2011. Cosmopolitanism, individuallevel values and cultural-level values: A crosscultural study. Journal of Business Research, 64: 934-943.

[8] Meyers-Levy, J. 1988. The influence of sex roles on judgement. Journal of Consumer Research, 14: 522-530.

[9] Riefler, P., Diamantopoulos, A., \& Siguaw, J. A. 2012. Cosmopolitan consumer as a target group for segmentation. Journal of International Business Studies, 43: 285-305.

[10] Javalgi, R. G., Khare, V. P., Gross, A. C., \& Scherer, R. F. 2005. An application of the consumer ethnocentrism model to French consumers. International Business Review, 14: 325-344.

[11] Josiassen, A., Assaf, A. G., \& Karpen, I. O. 2011. Consumer ethnocentrism and willingness to buy: Analyzing the role of three demographic consumer characteristics. International Marketing Review, 28(6): 627-646.
[12] Festervand, T. A., Lumpkin, J. R., \& Lundstrom, W. J. 1985. Consumer perceptions of imports: An update and extension. Akron Business and Economic Review, 16(1): 31-6.

[13] Sharma, S., Shimp, T. A., \& Shin, J. 1995. Consumer ethnocentrism: A test of antecedents and moderators. Journal of the Academy of Marketing Science, 23(1): 26-37.

[14] Han, C. Min. 1988. The role of consumer patriotism in the choice of domestic versus foreign products. Journal of Advertising Research, 28(3): 25-32.

[15] Bannister, J. P., \& Saunders, J.A. 1978. UK consumers' attitudes towards imports: The measurement of national stereotype image. European Journal of Marketing, 12: 562-570.

[16] Caruana, A., \& Magri, E. 1996. The effects of dogmatism and social class variables on consumer ethnocentrism in Malta. Marketing Intelligence \& Planning, 14(4): 39-44.

[17] Balabanis G., Diamantopoulos, A., Mueller, R. D., \& Melewar, T. C. 2001. The impact of nationalism, patriotism and internationalism on consumer ethnocentric tendencies. Journal of International Business Studies, 32(1): 157-176.

[18] Shennan, S. 2001. Demography and cultural innovation: A model and its implications for the emergence of modern human culture. Cambridge Archaeological Journal, 11: 5-16.

[19] Cleveland, M., \& Laroche, M. 2007. Acculturation to the global consumer culture: Scale development and research paradigm. Journal of Business Research, 60: 249-259.

[20] Nunnally, J. C. 1978. Psychometric theory, McGraw-Hill, New York: New York.

[21] Bagozzi, R. P. 1980. Causal models in marketing. New York: John Wiley \& Sons, Inc.

[22] Hair Jr. J. E, Black, W. C., Babin, B. J., Anderson, R., Tathum, R. 2006. Multivariate data analysis. $6^{\text {th }}$ ed. Upper Saddle River, NJ: Pearson-Prentice Hall.

[23] Shimp, T. A., \& Sharma, S. 1987. Consumer ethnocentrism: Construction and validation of the CETSCALE. Journal of Marketing Research, 24: 280-289. 